\title{
An approach to designing interactive decision aid for cardiac patients
}

\author{
Anandhi V Dhukaram \\ School of Electronic, Electrical and Computer Engineering \\ University of Birmingham \\ AVD016@bham.ac.uk
}

\author{
Chris Baber \\ School of Electronic, Electrical and Computer Engineering \\ University of Birmingham \\ c.baber@bham.ac.uk
}

\begin{abstract}
The design of interactive decision aids for patients is challenging because there are few if any guidelines for information design for such devices. In this paper, we look at designing an interactive decision aid through the use of Cognitive Work Analysis (CWA) for cardiac patient needs. We focus on three analysis phases: work domain analysis (WDA), control task analysis, and strategies analysis. We discuss these three phases of the CWA, how we collected user needs using focus groups, and how the content of support is represented in each of these three levels. Finally, we discuss how the three levels influenced our design recommendations and ideas for how the information is presented.
\end{abstract}

Decision aids, cognitive work analysis, work domain analysis.

\section{INTRODUCTION}

Cardiovascular Disease (CVD) accounts for almost half of all deaths in Europe, causing over 4.3 million deaths in Europe, with 268.8 million lost working days, which results in a per capita cost of 391 Euros $(57 \%$ of this is directly linked to health care, $21 \%$ to productivity losses and $22 \%$ to the cost of informal care provided by relatives and friends) (European Parliament Heart Group 2008).

In spite of the advances in management, CVD is associated with high rates of hospitalization, poor quality of life, and early death. Education initiatives, intended to improve patients' abilities to care for themselves, plays an important role in disease management programs (Dickson et al 2007). Programs that teach self-management seem to slow disease progression and prevent repeated and expensive hospital readmissions (Stromberg et al 2002, Hicks \& Holm 2003, Shipton 1997).

Self-management is an active learning process and relies on patient knowledge, experience, and receptivity to cues to maintain health through treatment adherence and symptom monitoring (Dickson et al 2007, Hicks \& Holm 2003, Riegel et al 2000). Managing CVD requires patients to identify symptoms and seek treatment quickly. Yet, our literature review and focus group studies have shown that lack of dietary discretion, medication compliance, and failure to detect symptoms and act early are found to be the primary contributors to acute hospitalisation (Dickson et al 2007). Therefore, Interactive decision support (referred to as Decision Aids, DAs) may help. DAs involve the use of interactive computer technology to present a variety of options to patients based on health status for effective decision making and to better manage themselves (Evans et al 2004, Brehaut et al 2008, Lin et al 2009, O'Brien et al 2009, Montori et al 2006, Elwyn et al 2006, Stacey et al 2008). When patients are involved in making decisions about day-to-day treatment they are likely to become less anxious and achieve better outcome from treatments (Satterfield et al 2009).

A meta-analysis of the effectiveness of decision aids with over sixty decision aids (Brehaut et al 2008) has shown that DAs improve the quality of decision relevant to a patient health status, in comparison to both standard care information documents and standard education programs. Decision Aids can be used to educate patients and enhance the quality of their decisions so as to reduce practice variations by (a) providing facts about the condition, options, outcomes, and probabilities that are relevant to the patient's health status (O'Connor et al 2007); (b) providing feature matching process (Hutton \& Klein 1999) in which certain changes in health status are highlighted and compared to past experiences; and (c) guiding patients in making decisions, e.g., in terms of lower decisional conflict (Barnato et al 2007), more active patient involvement in decision-making, and decreased levels of anxiety and distress (Lin et al 2009).

However, little research has been conducted to identify the relationships between the design of user interface and the information content of the DAs. This research is the first step in suggesting an 
approach for designing an interactive decision aid for cardiac patients using Cognitive Work Analysis and a review of existing user interfaces. This paper aims to provide: how the content of the decision system is defined, how to incorporate decision aids into an interactive, complex process of making such decisions and how the information is presented to the user.

\section{METHOD}

Cognitive Work Analysis (Jenkins et al 2009, Vincente 1999) is a structured framework for the analysis of complex socio-technical systems such as command and control (Chin et al 1999, Naikar 2001) or process control (Vincente 1999). In the medical domain, CWA has been applied to patient monitoring (Sanderson et al 2004), clinical displays (Effken et al 2001), intensive care units (Miller 2004) and teletriage (Hajdukiewicz et al 2001). This multifaceted framework allows the researcher to observe the complexity of human information behavior in complex systems. It is fair to say that the majority of previous applications of CWA have focused on experts in specific domains. In this paper, our focus on patients as decision makers allows us to explore how well the approach can accommodate the lay person or non-expert. Of course, the patients will be familiar with their own experience of their condition but might have less knowledge of the medical facts surrounding its treatment.

We have chosen CWA framework as it guides us through the process of answering the question of why the system exists; what activities are conducted with this system; how the information is processed and who is performing it. CWA has five levels of analysis: WDA, control task analysis, strategies analysis, social-organisational analysis, and work competency analysis. As this paper is focused on designing a decision aid for cardiac patients, we chose the following CWA analyses based on patient requirements to meet the objectives:

- WDA: requirement analysis for cardiac patient management (Naikar 2001)

- Control Task Analysis: to create rules and decision ladder analysis for diagnosis and management (Rasmussen \& Goodstein 1987)

- Strategies Analysis: interaction analysis for providing decision support solution (Chin et al 1999)

In the following sections, we discuss the information gathering phase using focus groups for CWA and discuss the three analytical phases:
WDA, decision ladder analysis, and strategies analysis. Finally, we present our review of existing user interfaces for mobile medical devices and how to represent the user requirement on the screen with an example scenario.

\subsection{Information Gathering: Focus Groups}

Focus group discussion is an effective way to gather information in which a small group (5-12) of participants gather to discuss a specified topic or an issue (Wong 2008). In the focus group the interviewer (also called as moderator) asks questions about a topic to the group and the group members exchange ideas and comments on each other's experiences or views.

Focus group studies have been used to explore a wide range of health and medical related issues, including: experiences of health care in relation to their heart condition, understanding of health risks, treatment preferences and impact on quality of life (Rasmussen \& Goodstein 1987 ); reducing CVD risks (Wong 2008) ; racial disparity in cardiac decision making(Kennelly \& Bowling 2001).

The purpose of our focus group was to gain insight into the patients' decision making for CVD, patients' perceptions, opinions and experience.

Figure 1: Word cloud based on focus group discussion

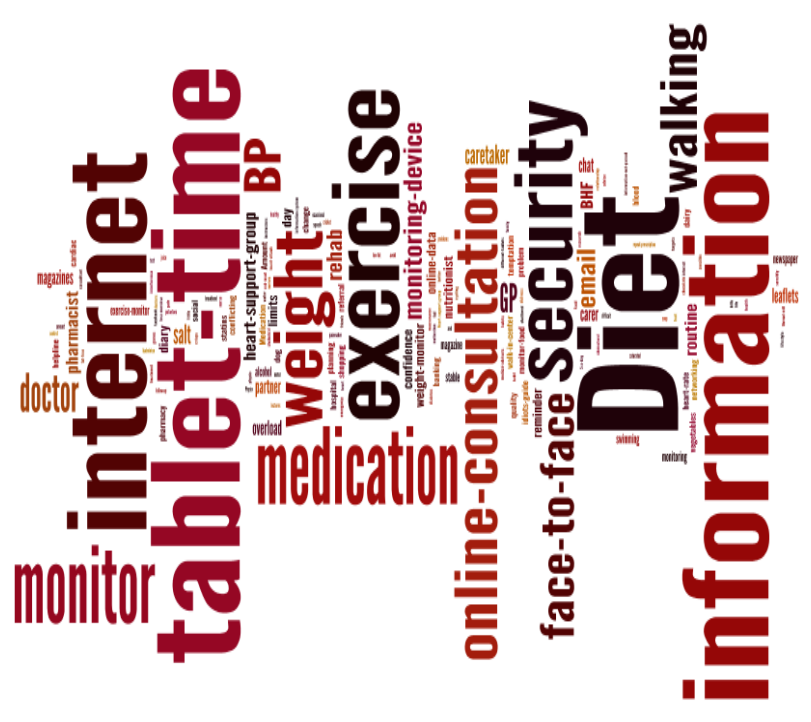

2.1.1. Participants

We conducted five focus group sessions covering West Midlands and Cheshire region with 35 patients and carers (13 females and 22 males). Participants were mostly in the age range of 60-69 years and were members of local heart support groups, diagnosed with cardio-vascular disease with an average history of 4 years. Participants were recruited by contacting various heart support group. Initial contact with the support group 
coordinators or president was either in person, email or by phone.

Each focus group included five to ten participants and was conducted in a setting that was convenient to the participants including: library, hospital and health club.

\subsubsection{Measures}

Semi-structured discussions were conducted with the focus group. With participant's permission, all discussions were audio recorded. Participants were asked to describe their decision-making, access to information about their health condition, experiences, exercise, diet, self-monitoring and technology acceptance for e-health. At the end of the interview, participants completed a brief questionnaire regarding their technology acceptance and knowledge.

\subsubsection{Data Analysis}

A word cloud was created based on the focus group discussion to gain insight into the needs of the patients' as shown in Figure 1.
We transcribed the focus group discussions and transcripts were divided into units each encompassing a single complete idea in relation to patient's decision-making requirements as show in Figure 2.

Our focus group study revealed that on a day-today basis, patients' are expected to make important medical decisions and management decisions on their tablet time, diet, exercise and health monitoring which require guidance and information for the patient to make informed decisions and take control of their health.

\begin{abstract}
"Because of the lack of the information it makes our decision different. If we had more information then maybe our decision wouldn't be different, maybe we would trust you know just jumping on a train and whizzing down to London for a day or something without having to plan but because the information is scare and so is our courage there is a lot of uncertainty and decision-making is ruled by uncertainty." (FG3, male3)
\end{abstract}

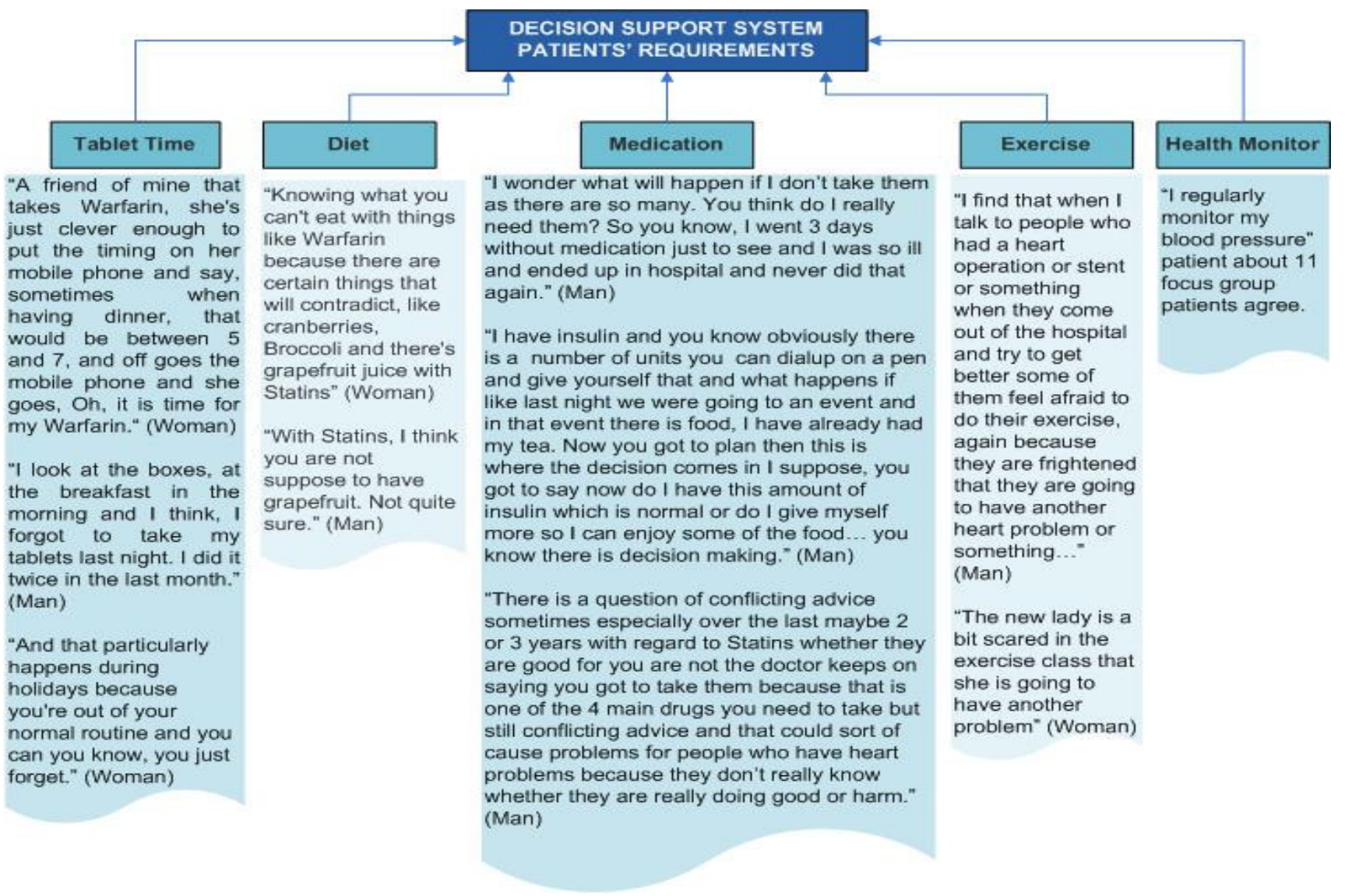

Figure 2: Phrases and quotes offered by participants are provided as illustration of the factors that emerged during the focus group discussions. 


\subsection{Analysis}

We start our analysis by finding out the role of CWA in relation to some of the patients' requirements (see Figure 2) in the following table.

Table 1: Patient's requirements and their role in CWA

\begin{tabular}{|l|l|}
\hline $\begin{array}{l}\text { Patient Decision } \\
\text { Needs }\end{array}$ & \multicolumn{1}{|c|}{ CWA } \\
\hline $\begin{array}{l}\text { Tablets: "Different } \\
\text { times so it is quite } \\
\text { complicated" }\end{array}$ & $\begin{array}{l}\text { Work domain relationships for } \\
\text { tablet time management. }\end{array}$ \\
\hline $\begin{array}{l}\text { Diet: "Can I have } \\
\text { grapefruit?" }\end{array}$ & $\begin{array}{l}\text { Work domain relationships on } \\
\text { tablets and its side effects in } \\
\text { relation to food and drink. } \\
\text { Decision ladder flow and } \\
\text { Strategies Analysis. }\end{array}$ \\
\hline $\begin{array}{l}\text { Medication: "What } \\
\text { will happen if I } \\
\text { don't take my } \\
\text { medication?" }\end{array}$ & $\begin{array}{l}\text { Decision ladder flow in relation } \\
\text { to patients' health status and } \\
\text { causes and effects option. }\end{array}$ \\
\hline $\begin{array}{l}\text { Exercise: "Bit } \\
\text { scared of doing } \\
\text { exercise" }\end{array}$ & $\begin{array}{l}\text { Work domain relationships for } \\
\text { exercise. Strategies for alerting } \\
\text { patient while exercising. }\end{array}$ \\
\hline $\begin{array}{l}\text { Monitoring: } \\
\text { automatically } \\
\text { monitor BP }\end{array}$ & $\begin{array}{l}\text { Work domain relationships for } \\
\text { monitoring. Strategies for } \\
\text { monitoring the patient. }\end{array}$ \\
\hline
\end{tabular}

\subsubsection{Work Domain Analysis (WDA)}

The first phase of WDA is used to describe the domain in which the activity takes place by specifying the scope of analysis independent of any goals or activities by building up an abstraction hierarchy $(\mathrm{AH}) . \mathrm{AH}$ is developed to include the decision support needs for the patients. We included the patient as well as various resources the decision aids would use.

To model the patient management for tablet-time, diet, medication, exercise and monitoring we used Hajdukiewicz for basic model of patient health as a starting point (Price et al 2009). We also map information in the $\mathrm{AH}$ model as it is evident from the focus group that patients need to be educated and information should be easily available for them to make decisions.

$\mathrm{AH}$ as shown in Figure 3 have five levels of abstraction. Each level of abstraction is given below:

- Functional purposes: represents the highlevel aims or objectives of the system. In this case, patient management.

- Values and priorities: represents the criteria for measuring whether the system can achieve the functional purpose aims.

- Purpose-related functions: represents the functions of the system that are needed to achieve the functional purposes.

- Object related processes: represents the physical context in which the system operates functional capabilities and limitations of the physical objects.

- Physical objects: represents the physical objects of the system.

The highlighted area in Figure 3 relate to the diet scenario that will be explained in the rest of this paper.

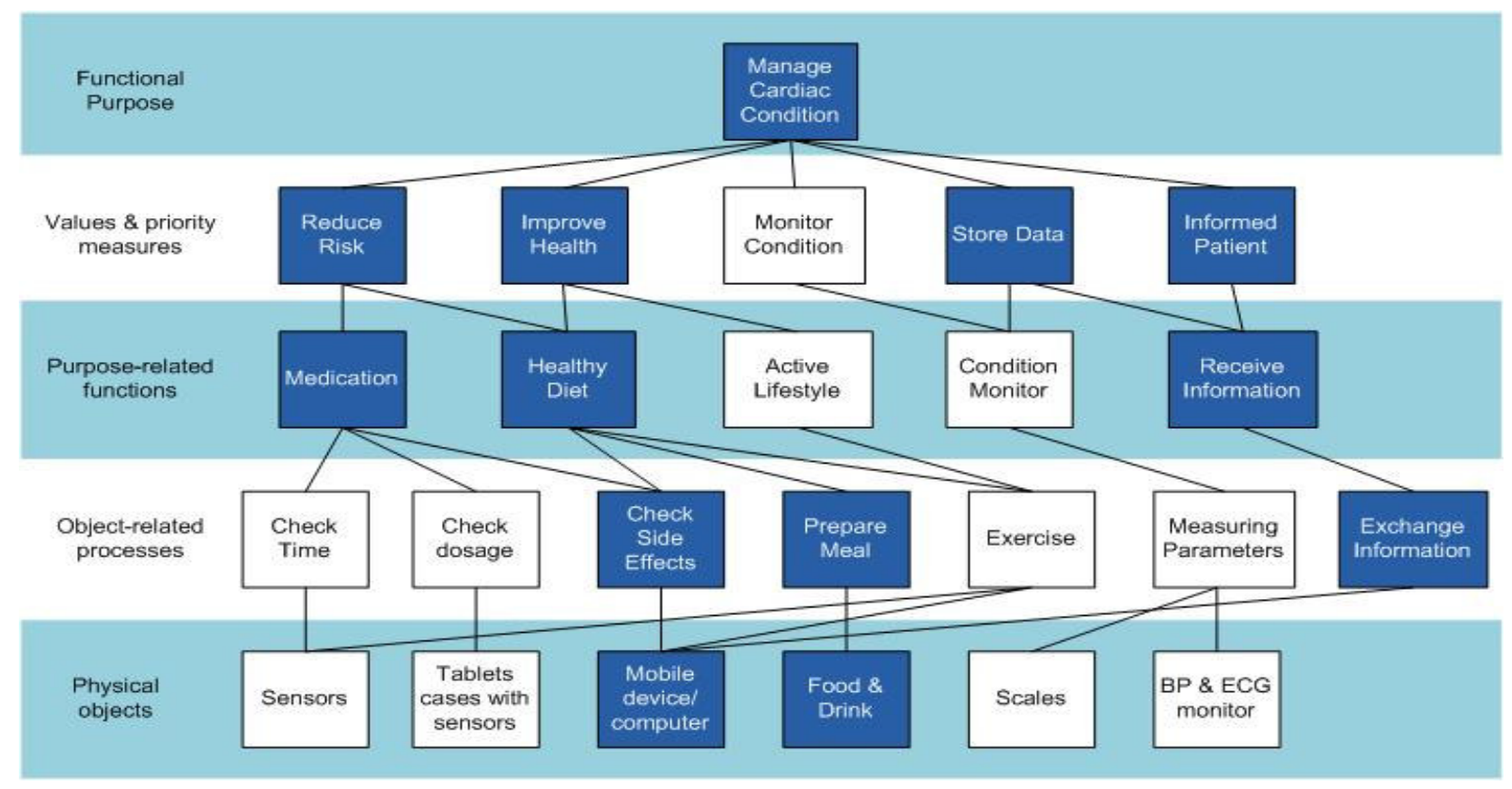

Figure 3: Abstraction hierarchy for patient management 


\subsubsection{Control Task Analysis}

In the first phase WDA we looked at the domain independent of activity to understand the design of the decision aids further it is advantageous to look at some of the requirements in more detail. In this phase we will be using the decision ladder to focus on what has to be achieved independent of how the task is conducted or who will be doing it.

An example of a patient requesting decision information is modelled onto the decision ladder shown in Figure 4. This example is taken from the focus group discussion:
"With Statins, I think you are not suppose to have grapefruit. Not quite sure." (FG1, male5)

Once a request is made by the patient the information is processed and attended. In the scenario for Figure 4 'Can I eat grapefruit?' as the system has got information stored in the database about the patient's health status it can speed up the process to bypass some of the steps in the decision to provide instruction to the patient.

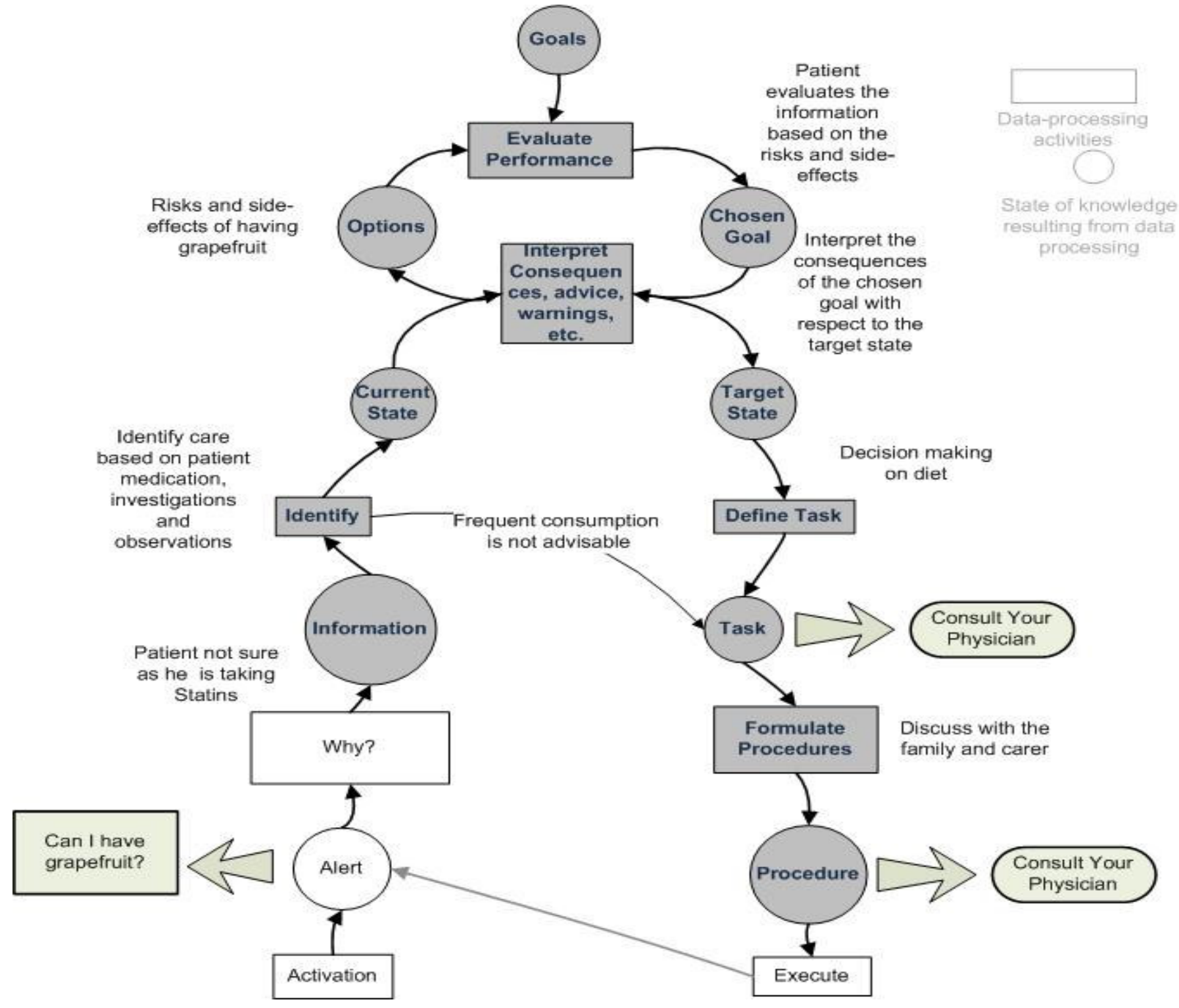

Figure 4: Decision ladder for diet

\subsubsection{Strategy Analysis}

The strategies analysis is a natural follow-up to the task analysis to solve actual problem like openended questions or questions based on symptoms.
We have demonstrated in Table 2 the strategies used in response to a question "Can I have grapefruit?" with the assumption that the system does not know the patients' medication. 
Table 2: An example of hypothetical strategies

\begin{tabular}{|l|l|}
\hline \multicolumn{1}{|c|}{ Strategy } & \multicolumn{1}{|c|}{ Question } \\
\hline "Can I have & What is your diet plan? \\
grapefruit?" & Do you have any discomfort? \\
& What side effects do you get \\
& from different foods? \\
& Are you taking Statins or \\
& Warfarin? \\
& What foods should you avoid? \\
& How do different foods interact \\
& with medication? \\
\hline
\end{tabular}

A key aspect of the approach being advocated is the interaction between patient and device to refine and reformulate a question in order to receive appropriate advice. At one level an essential aspect of self-management is the ability to ask the right questions. Through the decision ladder, it is possible to develop a structured approach to question asking that allow patient and DA to reach a view.

\subsection{Design}

Having outlined the ways in which patients can be encouraged to ask appropriate questions to support their decision making the next stage is to design a user interface that could run on a mobile device to support patient decision making. As there are no standards to date governing the design of DAs we examined a wide range of publicly available mobile medical devices in order to determine common features and functions.

We collected 87 screen shots of currently available decision support products for review. By reviewing the literature and through initial assessment by authors we identified 23 key features that were essential for a good user interface. We then created an excel spreadsheet with 87 screen shots and 23 features and asked 7 researchers what features was present on each of the screen shots. Based on the feedback received from the researchers Factor Analysis was performed on the subjective rating of each example screen shot against the identified features. The analysis employed Principal Component Analysis with variant rotation using Kaiser Normalization which emerged after 11 rotations.

This resulted in 8 factors which accounted for $72 \%$ of the variance. Using a cut-off point of 0.45 , features were assigned to uniquely belong to one of the factors as shown in Table 3.

Table 3: Factor Analysis results

\begin{tabular}{|c|c|c|c|}
\hline \multicolumn{4}{|c|}{ FACTOR ANALYSIS } \\
\hline FACTOR & $\begin{array}{l}\text { \% OF } \\
\text { VARIANCE }\end{array}$ & FEATURES & DESCRIPTION \\
\hline $\begin{array}{l}\text { 1. Interaction } \\
\text { Management }\end{array}$ & $18 \%$ & $\begin{array}{l}\text { Icon }+ \text { Symbols }(0.749) \\
\text { List of items }(0.699) \\
\text { Control panel(0.835) }\end{array}$ & $\begin{array}{l}\text { Provides high-level options for user to } \\
\text { manage their interaction with the } \\
\text { application. }\end{array}$ \\
\hline $\begin{array}{l}\text { 2. Decision support } \\
\text { information }\end{array}$ & $13 \%$ & $\begin{array}{l}\text { Larger text(0.888) } \\
\text { Help/ Options menu(0.459) }\end{array}$ & $\begin{array}{l}\text { Receive decision support information. } \\
\text { Example: Diet advice, side effects. }\end{array}$ \\
\hline 3. Alerts and Prompts & $12 \%$ & $\begin{array}{l}\text { Colours }(0.645) \\
\text { Traffic lights }(0.640) \\
\text { Question and answer in the } \\
\text { same screen }(0.709)\end{array}$ & $\begin{array}{l}\text { Manually-initiated or automated clinical } \\
\text { reminder is sent to the patient. For } \\
\text { example - "Have you taken the tablets?" } \\
\text { or tablet time. }\end{array}$ \\
\hline $\begin{array}{l}\text { 4. Patient Details and } \\
\text { input forms }\end{array}$ & $7 \%$ & $\begin{array}{l}\text { Input textbox }(0.836) \\
\text { Drop down box }(0.727)\end{array}$ & $\begin{array}{l}\text { Provides user with a form to fill in. } \\
\text { Example: patient details entry form, } \\
\text { medication and diet. }\end{array}$ \\
\hline $\begin{array}{l}\text { 5. Health Data and } \\
\text { monitoring }\end{array}$ & $7 \%$ & $\begin{array}{l}\text { Graphical display }(0.822) \\
\text { Health meter }(0.862)\end{array}$ & $\begin{array}{l}\text { Provide ECG, BP and other health } \\
\text { related data in the way user would } \\
\text { understand. }\end{array}$ \\
\hline 6. Information sources & $6 \%$ & $\begin{array}{l}\text { Scroll bars }(0.711) \\
\text { Background } \\
\text { information }(0.778)\end{array}$ & $\begin{array}{l}\text { Allow patient to access sources of } \\
\text { information such as leaflets. }\end{array}$ \\
\hline 7. External services & $5 \%$ & $\begin{array}{l}\text { Service Cost(0.845) } \\
\text { Warnings(.537) }\end{array}$ & $\begin{array}{l}\text { This can be used to warn the patient if } \\
\text { there are any charges involved for the } \\
\text { services used by the patient. }\end{array}$ \\
\hline 8. Media Player & $5 \%$ & $\begin{array}{l}\text { Videos }(0.830) \\
\text { Images }(0.588)\end{array}$ & $\begin{array}{l}\text { Used to provide guidance to patients for } \\
\text { "how to use a BP monitor?" }\end{array}$ \\
\hline
\end{tabular}




\section{DISCUSSION}

A demo application was developed using J2ME technology and the screen shots for the scenario "Can I eat grapefruit?" is shown in Figure 5 along with the design rationale in Table 4 . Table 4 indicates the manner in which design decisions were made for this version of the user interface. Each screen of the user interface can be related to either sections of the $\mathrm{AH}$ or to the Control Task Analysis or Strategies Analysis. The implication of course, is that further screens correspond to each of the other sections in the $\mathrm{AH}$. In addition to showing the relation between CWA and screens, Table 4 also shows the primary factors (from factor analysis) that were deemed to define the appearance of that particular screen. Table 4 also provides a short description for each screen.

CWA is useful to explore patient decision making. DAs design can be guided by CWA. Challenges are:

- How to ensure universal accessibility and platform support for various mobile devices such as Android, iPhone, Windows, Symbian, etc?

- How to automate the data collection process and encourage the user to provide data?

- How to support structured and unstructured questions to encourage people to be informed patients?

Table 4: Design Rationale

\begin{tabular}{|l|l|l|l|}
\hline FIGURE & CWA & FACTOR & DESCRIPTION \\
\hline $5 a$ & Abstraction hierarchy (Figure 3) & $\begin{array}{l}\text { Interaction } \\
\text { Management }\end{array}$ & $\begin{array}{l}\text { Provides main functions of the AH process that is } \\
\text { needed by the patient to manage cardiac conditions. }\end{array}$ \\
\hline $5 \mathrm{~b}$ & $\begin{array}{l}\text { Abstraction Hierarchy (Figure } \\
\text { 3): Values \& priority measures } \\
- \text { Improve health, Store data } \\
\text { and Informed patient. }\end{array}$ & $\begin{array}{l}\text { Interaction } \\
\text { Management }\end{array}$ & $\begin{array}{l}\text { This screen provides all the information that is } \\
\text { needed for the patients' diet management. }\end{array}$ \\
\hline $5 \mathrm{c}$ & $\begin{array}{l}\text { Abstraction Hierarchy (Figure } \\
\text { 3): Physical objects - Mobile } \\
\text { device/ Computer }\end{array}$ & $\begin{array}{l}\text { Patient Details } \\
\text { and input forms }\end{array}$ & $\begin{array}{l}\text { The patient initiates using structured or unstructured } \\
\text { questions the patient would like to ask, or } \\
\text { description of symptoms or problems the patient } \\
\text { wishes to make a decision about. }\end{array}$ \\
\hline $5 \mathrm{~d}$ & $\begin{array}{l}\text { Control Task Analysis (Figure } \\
\text { 4) and Strategies Analysis } \\
\text { (Table 2) }\end{array}$ & $\begin{array}{l}\text { Alerts and } \\
\text { Prompts }\end{array}$ & $\begin{array}{l}\text { This is an optional screen that will be displayed if the } \\
\text { system is not aware of the patient medication. }\end{array}$ \\
\hline $5 \mathrm{e}$ & $\begin{array}{l}\text { Control Task Analysis (Figure } \\
\text { 4) }\end{array}$ & $\begin{array}{l}\text { Decision support } \\
\text { information }\end{array}$ & $\begin{array}{l}\text { Evaluate patient question and medication and health } \\
\text { status. Once the most appropriate data is } \\
\text { determined, the diet advice response is created. } \\
\text { After reading the advice the patient can update the } \\
\text { diet records, noting the details of the interaction. }\end{array}$ \\
\hline
\end{tabular}
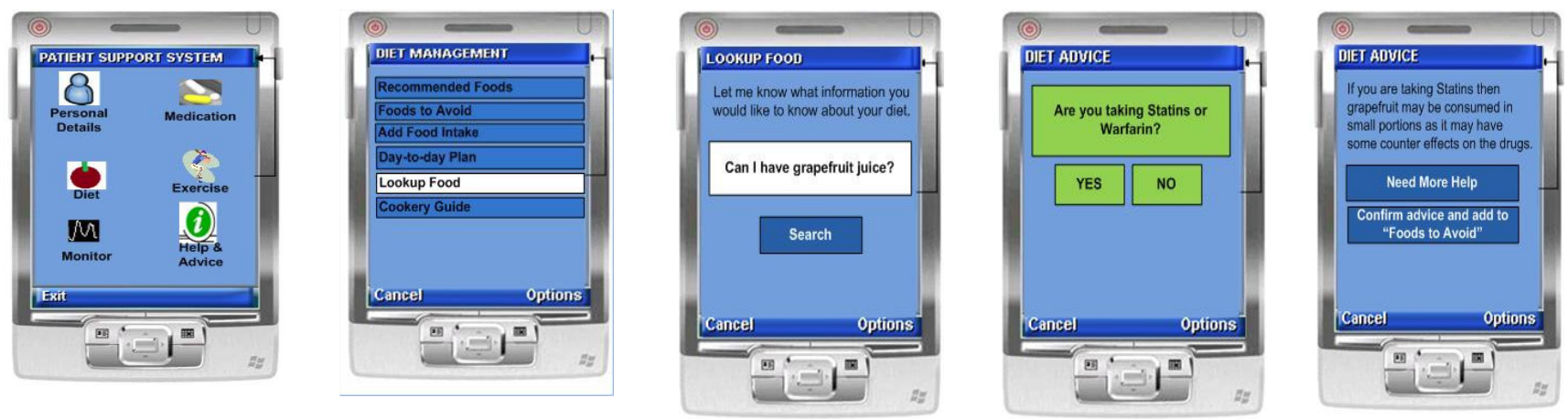

Figure 5: User interface screen shots 


\section{REFERENCES}

European Parliament Heart Group (EHN) (2008) Cardiovascular Disease Statistics. http://www.ehnheart.org/cdv-statistics.html (22 January, 2011)

Dickson VV, Tkacs N, Riegel B. (2007) Cognitive influences on self-management decision making in persons with heart failure. Am Heart J, 154, 42431.

Stromberg A., Ahlen H, Fridlund B, and Dahlstrom U. (2002). Interactive education on CD-ROM - a new tool in the education of heart failure patients. Patient Education and Counseling, 46, 75-81.

Hicks FD, Holm K. (2003) Self-management decision influences in heart failure: a preliminary investigation. Clin Nurs Res, 12, 69-84.

Shipton SL. (1997) Congestive heart failure readmission. Home Care Provider, 2, 171-175

Riegel B, Carlson B and Glaser D (2000). Development and testing of a clinical tool measuring self-management of heart failure. Heart \& Lung: The Journal of Acute and Critical Care, 29, 4-12.

Evans R, Elwyn G, Edwards A (2004). Making interactive decision support for patients a reality. Inform Prim Care, 12, 109-13.

Brehaut J, Lott A, Fergusson D, et al (2008). Can patient decision aids help people make good decisions about participating in clinical trials? A study protocol. Implement Sci, 3, 38.

Lin GA, Aaronson DS, Knight SJ, et al (2009). Patient Decision Aids for Prostate Cancer Treatment: A Systematic Review of the Literature. CA Cancer J Clin, 59, 379-390.

O'Brien MA, Whelan TJ, Villasis-Keever $M$, et al (2009). Are Cancer-Related Decision Aids Effective? A Systematic Review and Meta-Analysis. $\mathrm{J}$ Clin Oncol, 27, 974-985.

Montori VM, Weymiller AJ, Jones LA, et al (2006). $A$ decision aid enhanced adherence with statins in patients with type 2 diabetes - report from a randomized trial of a decision aid in a specialty setting. The 28th Annual Meeting of the Society for Medical Decision Making, October 15-18, 2006 Boston, MA.

Elwyn G, O'Connor A, Stacey D, et al. (2006) Developing a quality criteria framework for patient decision aids: online international Delphi consensus process. BMJ, 333-417.

Stacey D, Samant R and Bennett C. (2008) Decision Making in Oncology: A Review of Patient Decision Aids to Support Patient Participation. CA Cancer J Clin, 58, 293-304.

Satterfield D, Kang SR, Bruski P, et al. (2009) Medical Decision Aides: An Evaluation Methodology for Information Design. IASDR, 18-22 October, 2009, Seoul Korea.

O'Connor A, Wennberg JE, France L, et al (2007). Toward The 'Tipping Point': Decision Aids And
Informed Patient Choice. Health Affairs, 26, 716725.

Hutton R, Klein G. (1999) Expert Decision Making. Syst Eng, 2, 32-45.

Barnato A, Llewellyn-Thomas HA, et al. (2007) Communication and Decision Making in Cancer Care: Setting Research Priorities for Decision Support/Patients' Decision Aids. Med Decis Making, 27, 626-634.

Calvin K.L. Or, Ben-Tzion Karsh (2006). The Patient Technology Model (PTAM) For Homecare patients with chronic illness. Proceedings of the Human Factors and Ergonomics Society Annual Meeting, October 2006, 50:10, 989-993.

Jenkins DP, Stanton NA, et al (2009). Cognitive Work Analysis: Coping with Complexity. Avebury: Ashgate.

Vicente, K.J. 1999. Cognitive Work Analysis : Toward Safe, Productive, and Healthy ComputerBased Work. CRC Press; 1 edition.

Chin M, Sanderson P, Watson M, (1999). Cognitive work analysis of the command and control work domain. Proceedings of the 1999 Command and Control Research and Technology Symposium.

Naikar N and Sanderson PM (2001). Evaluating design proposals for complex systems with work domain analysis. Human Factors, 43, 529-542.

Sanderson P, Crawford J, Savill A, Watson M, and Russell WJ (2004). Visual and auditory attention in patient monitoring: a formative analysis, Cognition, Technology \& Work, 6, 172-185.

Effken J, Loeb R, Johnson K, et al. (2001) Using cognitive work analysis to design clinical displays. Stud Health Technol Inform, 84,127-31.

Miller, A. (2004). A work domain analysis framework for modelling intensive care unit patients. Cognition, Technology and Work. 6:4, 207-222.

Hajdukiewicz, JR, Vicente KJ, Doyle DJ, Milgram, $P$, and Burns CM (2001). Modeling a medical environment: an ontology for integrated medical informatics design. International Journal of Medical Informatics, 62, 79-99.

Rasmussen J and Goodstein LP (1987). Decision support in supervisory control of high-risk industrial systems, Automatica, 23, 663-671.

Wong LP (2008). Focus group discussion: a tool for health and medical research. Singapore Med J. 49:3, 256-60.

Kennelly C, Bowling A (2001). Suffering in deference: a focus group study of older cardiac patients' preferences for treatment and perceptions of risk. Qual Health Car, 10, i23-i28.

Price HC, Dudley C, Barrow B, et al (2009). Use of focus groups to develop methods to communicate cardiovascular disease risk and potential for risk reduction to people with type 2 diabetes. Fam Pract, 26, 351-8

Ferguson JA, Weinberger M, Westmoreland GR, et al (1998). Racial Disparity in Cardiac Decision Making. Arch Intern Med, 158, 1450-1453. 